\title{
Model of Sterile Intestine of Mices with Normal Microfloras: Histological and Ultrastructural Visualization Formation Kyst Organ-Like Intestine for the Study of Interaction of Pathogen Agents with the Host Sterile Intestine
}

\author{
Karlen Hovnanyan \\ Institute of Molecular Biology NAS RA, Yerevan, Armenia \\ Email: hovkarl@mail.ru
}

Received 7 April 2014; revised 12 May 2014; accepted 23 May 2014

Copyright (C) 2014 by author and OALib.

This work is licensed under the Creative Commons Attribution International License (CC BY).

http://creativecommons.org/licenses/by/4.0/

(c) (i) Open Access

\begin{abstract}
For obtainment of the isolated sterile intestine, inbred lines of mice C3HA, CBA, C57BL/6, BalB/c are used at same time; it is carried out transplantation of small and large intestines of embryons corresponding lines of mice subcutaneously in adult singen mice. In capacite of test objects we make use of cultures of Salmonella typhimurium. The side of organ like kysts of isolated sterile of small and large intestines' models on the histological and transmission electron-microscopic (TEM) preparations have their own typical composition. In case of electron-microscopic examination of steril small intestine they were revealed microvillus of epithelium, Salmonella typhimurium in lining epithelium and phagosoma of lymphoid cells of lamina propria of mucose.
\end{abstract}

\section{Keywords}

Sterile Intestine, Model, Electron Microscopy, Ultrastructura, Parasit-Host

\section{Introduction}

From the literature it is known reception gnotbiotic animals [1] [2]. It is known, also, that along with not purebred experimental animals [3]. Among them the most applicable are the following: contamination of ordinary 
experimental animals by pathogenic microorganisms culture per os or per rectum, insert of pathogenic microorganisms in small intestine loop or in intestinum caecum [4]-[6], as well as contamination of tissues culture [7]. Separate authors experimentally modelled germfree and gnotbiotic animal models [1] [2] [8]. Gnotobiology has shown that ability to live of live organisms without accompanying microflora is possible. Gnotobiont animals give the chance to use various species of microorganisms for creation at animals operated parasitocenos, and also to find out the mechanism interactions associates of parasitocenos in intestines and cavitary in organism spaces in system a parasite-host. However, these models have some certain defects. Lack of reception gnotbiotic animals is caused with observance of a special mode that demands the big material inputs: in case of special sterile isolators (boxs) availability, as well as barrier type premises, sterile air supply, diet keeping and sterile food usage, air (ventilation) [8]. In comparison with animals grown up in usual conditions, sterile animals, in particular experimental animals with sterile intestines, have one more lack: the expressed physiological deviations which cannot provide proper response at interaction with various pathogen agents at realisation of researches of features of their interactions.

The aim of the given work is maintenance of high probability of reception of the isolated sterile intestines at experimental linear inbred of mice with normal microflora and ways of their interaction with salmonellas.

\section{Material and Methods}

\subsection{Experimental Animals}

For this aim there used inbred mice line BALB/C, CBA, C3HA male and female. Experimentally received sterile gastroenteric tract of the embryo, divided into thin and thick parts of intestine, was reduced to fragments in the cold by ophthalmic scissors on pieces 1 - $2 \mathrm{~mm}$ size, placed into Hanks medium or 199 with antibiotics (penicillin and streptomycin) and, after lavage by fresh solution of the medium, the pieces of stomach, small and large intestine were inserted by tuberculin syringe subcutaneously. To singen newborn mice in amount of $0.1 \mathrm{ml}$, keeping all rules of asepsis. To avoid the inserted material leakage the place of puncture in newborn animals was glued by special glue, used in cases of microtrauma and the study of animals was performed every 7 - 10 days in order to establish the transplant growth.

\subsection{Bacteriological Assays}

As a test-object there was used the bacterial flora for sample of kyst model intestine. For contaminating of inbred mice by sterile transport 18-hours culture $S$. typhimurium (strain N 546) mice BALB/C, CBA, C3HA line after suction of contents were inserted 18-hours Salmonella culture $0.01 \mathrm{ml}$ suspension in sterils intestine cavity in amount of 500,000 bacteria by tuberculin suringe thin neeble puncture, preliminary processed by iodine and alcohol, by fuher lubricating the puncture place with special glue for microtrauma and by lubricating iodine. For determination of Saimonella internalization and generalization in differen organs there was performed bacteriological analysis of blood, lymphoid nodule, liver, pleen, ungs, kidnues with bio-samples inoculation on beef-extract broth with further re-inoculation on Wilson-Blair and Ploskirev bismuth sulfite medium (depending on experiment aim the euthanasia of experiment animals eith sterile intestine was performed eithin the period of 5 minutes till 7 days after contamination).

\subsection{Interaction Salmonella with the Peritoneal Macrophags}

For study the peculiarities of Salmonella interaction with peritoneal macrophages in vitro in culture and in vivo there were used both line (BALB/c, C3HA), and white breedless six-week-old mice. Peritoneal macrophages were cultivated in test-cups with integmentary glasses and with Hanks solution. Having an aim to study ultrastructural aspects of Salmonella interaction with macrophages in vivo the mice were intraperitoneally contaminated by the suspension of 18-hours culture $S$. typhimurium with the further receipt of peritoneal exudates. After the contamination the macrophages were fixed in different period of time after the incubation with Salmonella (30 minutes - 2 hours).

\subsection{Histological Assays}

After forming of subcutaneous tumor which is an intestine kysts in 7 - 10 days, for histological and electronic- 
microscopic study the pieces of sterile iontestine were taken for fixation by $10 \%$ buffered formalin solution and glutaraldehyd according to methodics. Histological sections were stained by hematoxylin-eosin, observed and micropictured in light microscope "Amplival”.

\subsection{Electronmicroscopic Assay}

The fixation of experimental biosamples (pieces of sterile intestine, macrophages) were performed by $2.5 \%$ solution of glutaraldehydeon cacodylate buffer, as well by mixture of paraformaldehyde, glutardehyde and picrinic acid [9]. Post-fixation has been continued with the help of $1 \%$ tetraoxid osmium solution on the same buffer at room temperature during not less than 1 hour. Dehydration of biosamples in ethanol, acetone of increasing concentration, with further covering by epon 812 and araldite. Samples polymerization poured in capsules BEEM type has performed at $37^{\circ} \mathrm{C}$ and $60^{\circ} \mathrm{C}$ during 48 hours, and ultrathin sections received on ultramicrotomes "Reichert Young”, have been contrasted by aqueous solution of uranyl acetate and citric acid lead [10] and studied in transmission electron microscopes: Tesla-500 (Tesla, Chekhia), JEM-100B (JEOL, Japan).

\section{Results and Discussion}

\subsection{Generalization Salmonella after Contamination}

As have shown results of bacteriological researches of a salmonella from a cavity of sterile intestines, generalization the listed bodies, disseminations in the shortest terms (in 5 minutes) after infection. The established generalization salmonella in lymphoid nodules, a liver, a spleen, kidneys, easy, blood testifies to their penetration into the noticed biological systems of an organism hematogen a way that proves to be true also revealing salmonella in blood. The received results of our supervision coincide with the data of other authors bacteriological researches concerning the study of Salmonella generalization dynamics on the early contamination stage in rabbits [11].

\subsection{Histological and Electronmicroscopic Assay Kyst and Epithelial Layer Model of Sterile Intestine of Inbred Mice}

The usage of light and electron-microscopy investigation methods allowed to reveal the peculiarities of the ultrastructural organization of epithelial layer of sterile small and large intestine model (Figures 1-3), shown similarity as regards an ultrastructure with epithelium thin and thick gut of usual experimental animals.

Electronmicroscopic study of Salmonella interaction with sterile intestine showed that Salmonella penetrate in interepithelial area from the sterile intestine kyst lumen (Figure 4 and Figure 5), then the lamina propria and meet there in lymphoid cells both phagosoma and without restrictive membrane, keeping the typical ultrastructural organization for gram-negative bacterium. In the lamina propria of the intestin the cellular compound of lymphoid elements (plasmocytes, eosinophils, lymphocytes, macrophages) is typical for intestinal invasion.

\subsection{Interaction Salmonella with the Macrophages}

Received data tell about the adaptation and tropism of Salmonella in macrophages by the way of additional layer

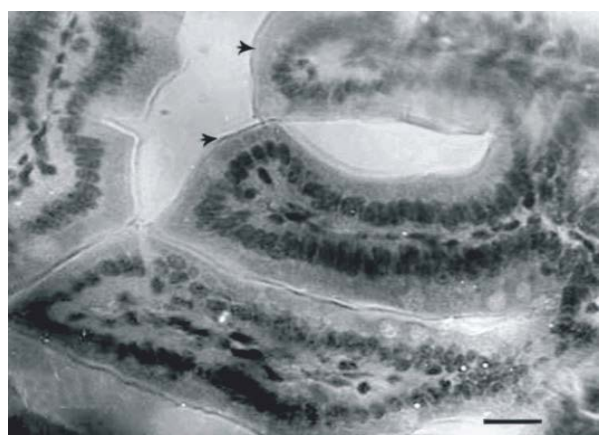

Figure 1. Epithelial tegmentum of the sterile large intestine inbreds mice: colored by hematoxylin-eosin. Magn. $\times 1000$. 


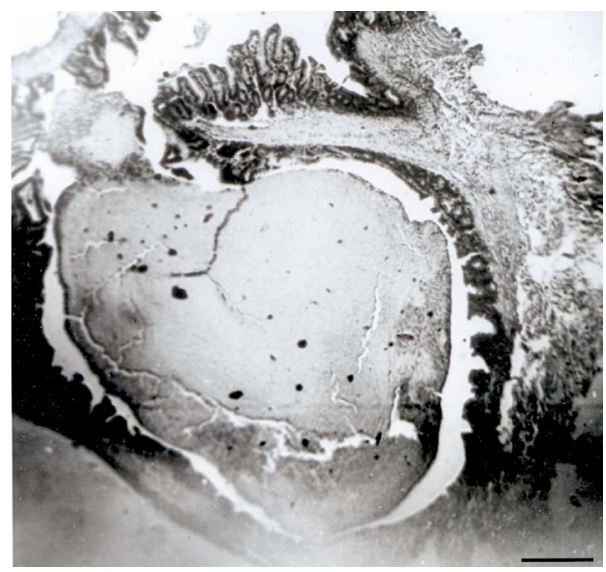

Figure 2. The kyst of the model of sterile large intestine. Magn. $\times 1000$.

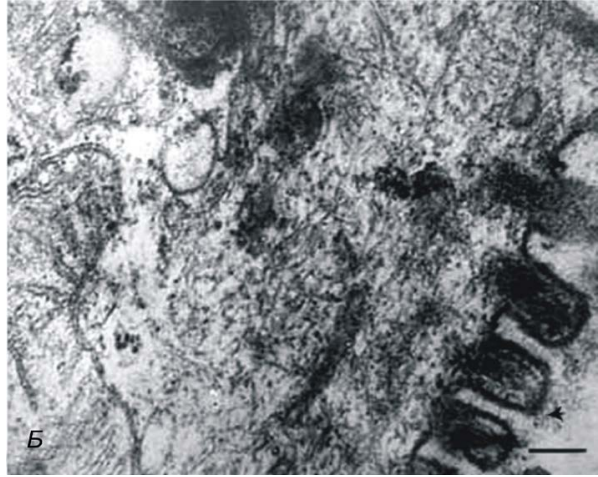

Figure 3. TEM. Microvilli of epithelial tegmentum the sterile large intestine. Scale bar: $0.5 \mu \mathrm{m}$.

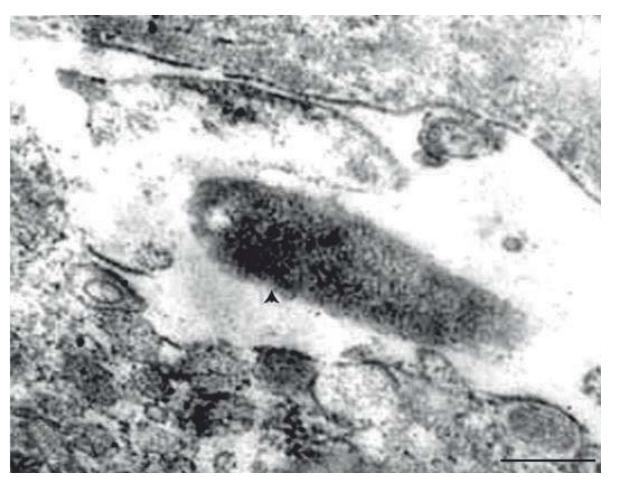

Figure 4. TEM. Epithelial tegmentum of the large intestine. Salm. typhimurium in interepithelial area. Scale bar: $0.5 \mu \mathrm{m}$.

formation on the external membrane of the cellular wall, L-transforming of bacteria and suppressing phagosomal-lisosomal activity of the host cells (Figure 6 and Figure 7). The received results are in well conformity with the literature data concerning the character of salmonella and macrophages interaction [8].

\section{Conclusion}

Thus, the model offered by us for interaction studying salmonella and other pathogen agents of intestinal infections with the isolated sterile intestines at experimental linear inbred of mice with normal microflora is adequate, 


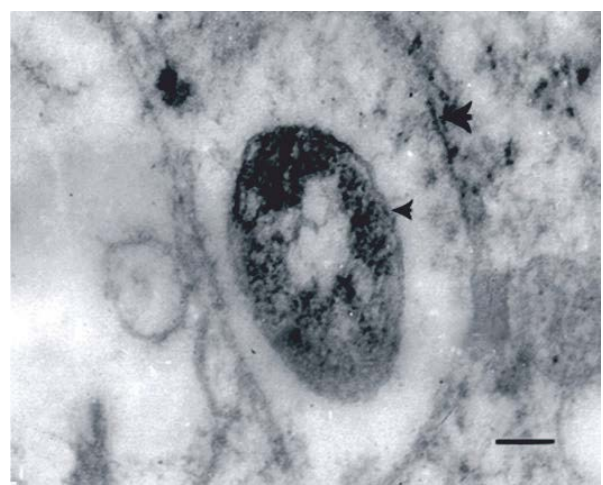

Figure 5. TEM. Salm.typhimurium in phagosoma of the macrophage. Scale: $0.5 \mu \mathrm{m}$.

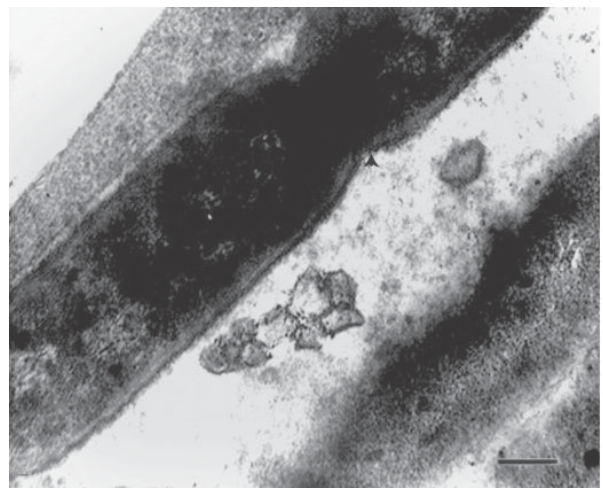

Figure 6. TEM. The division of Salm. typhimurium in phagosoma of the macrophage. Scale bar: $0.5 \mu \mathrm{m}$.

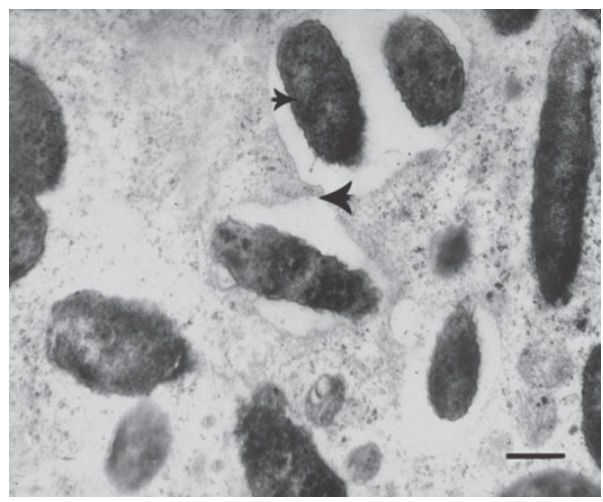

Figure 7. TEM. Salm. typhimurium in phagosoma of the macrophage. Scale bar: $0.5 \mu \mathrm{m}$.

accessible, simple: it is easy and it is widely possible to apply in laboratory practice.

\section{Acknowledgements}

The study was done within the framework supported by Ministry of Education and Science of the Republic of Armenia (Basic support).

\section{References}

[1] Wostmann, B.S. (1996) Germfree and Gnotobiotic Animal Models: Background and Applications. CRC Press, Inc., 
Boca Raton, 208.

[2] Reyniers, JA (1959) Germfree Vertebrates: Present Status. Annals of the New York Academy of Sciences, 78, 3-16. http://dx.doi.org/10.1111/j.1749-6632.1959.tb53091.x

[3] Svedsen, P. and Hau, J. (1994) Handbook of Laboratory Animal Science. Vol. II: Animal Models, CRC Press, Inc., Boca Raton, 224.

[4] Astafyev B.A., Yarotsckiim, L.S. and Lebedeva, M.N. (1989) Experimental Models of Parasitoses in Biology and Medicine. Nauka Press, Moscow, 279.

[5] Voyno-Yasenecki, M.V. (1981) Biology and Pathology of Infections Processings. “Medicina” Press, St.-Petersburg, 207.

[6] Metchnikoff, E. (1908) Études sur la flore intestinale. Annales de l’Institut Pasteur, 22, 929-955.

[7] Gostev, V.V., Bondarenko, V.M., Marchenko, V.G. and Klitsunova, N.V. (1986) Ultrastructural Aspects of Process Interaction Salmonella typhi with Cages of line L929. The Journal of Microbiology, 5, 34-37.

[8] Chakhava, O.V., Mountain, E. and Ruban, S.Z. (1982) Microbiological and Immunological of Bases of Gnotobiology. Medicina Press, Moscow, 160.

[9] Ito, S. and Karnovsky, M.J. (1968) Formaldehyde-Glutaraldehyde Fixatives Containing Trinitrocompounds. The Journal of Cell Biology, 39, 168A-169A.

[10] Venable, J.H. and Coggeshall, R. (1965) A Simplified Lead Citrate Stain For Use in Electron Microscopy. Journal of Cell Biology, 25, 407-408. http://dx.doi.org/10.1083/jcb.25.2.407

[11] Ghukasyan, G.B., Tonoyan, I.A. and Tendetnik, Y.Y. (1983) Primary and Secondary Localisation of Salmonellas in Experiment. Proceeding of Theses of Reports of 3rd Republican Congress of Epidemiologists, Microbiologists and Parasitologists, Yerevan, 20-22 September 1983, 35-36. 